\title{
Soft power indio: la experiencia de ser becaria ITEC
}

Sabrina Victoria Olivera ${ }^{1}$

\section{Contribución en la Sección Política Internacional}

El gobierno de India, por intermedio de su Ministerio de Asuntos Exteriores, ofrece a más de 160 países del mundo un programa de becas denominado Indian Technical and Economic Cooperation (ITEC). Este tipo de cooperación es una expresión del soft power o poder blando indio, definido por Nye como la capacidad de modificar las preferencias de otros estados mediante fuentes inmateriales como la atracción ideológica y cultural (Nye, 2008; Hanson, 2012). Si bien India ha desplegado acciones de poder blando desde tiempos anteriores al surgimiento de este concepto, en la actualidad puede considerarse a la India como un país "exportador" de su cultura (Hanson, 2012).

Empero, las becas ITEC son subutilizadas por Latinoamérica (BID, 2017) y su difusión aún puede ser mejorada. Vale tener presente que la oferta de cursos es muy amplia: están relacionados con las más diversas disciplinas, son de variable duración -pueden extenderse por dos semanas hasta inclusive un año- y no implican erogación alguna para los postulantes. El programa incluye el pasaje de avión, el hospedaje, la alimentación, los aranceles del curso y, además, se percibe un estipendio para solventar los gastos propios de la estadía. Claro que, más allá de lo atractiva que la propuesta pueda resultar, el postulante, a más de afrontar las varias horas de viaje, debe estar dispuesto a abrirse al desafío del intercambio intercultural que supone la permanencia en la India y la convivencia con participantes de muchos otros países.

En el año 2017, la autora del artículo decidió aplicar a uno de los cursos ofrecidos en el programa, titulado "Crédito Rural para la Reducción de la Pobreza", de una duración de cuatro semanas, en la ciudad de Hyderabad (estado de Telangana). La elección obedeció a la coincidencia de sus contenidos con la tesis de Maestría en Relaciones Internacionales, de la autora. Consideró que, de resultar seleccionada, podría verificar in situ aquello que durante años estudió a través de artículos, libros, etc. y no se equivocó.

En tal sentido, resulta valioso comentar los pasos por lo que su experiencia atravesó. Como primer paso, uno debe saber que aplicar a una beca no es un trámite sencillo, pero tampoco imposible. Se refiere a que completar los formularios, obtener las autorizaciones laborales, recopilar documentación relevante que respalde la postulación, realizarse un

\footnotetext{
1 Abogada (UBA) y Maestranda en Relaciones Internacionales (USAL). Es autora de distintas publicaciones y miembro del Grupo de Trabajo sobre India, del Comité de Asuntos Asiáticos, del Consejo Argentino para las Relaciones Internacionales (C.A.R.I.).
} 
chequeo médico y aplicarse vacunas, insume un tiempo del que es preciso disponer pero, a la luz de la experiencia, el esfuerzo cobra sentido. En este proceso, resulta fundamental el acompañamiento y posibilidad de consulta a la Embajada de la República de la India en Argentina y a la Dirección General de Cooperación Internacional, del Ministerio de Relaciones Exteriores y Culto, de la República Argentina.

Una vez enviada la aplicación de la beca -tanto por la página web de ITEC como por intermedio de la Cancillería argentina-, el segundo requisito es tener una actitud paciente frente al curso burocrático, propio de las estructuras de becas y, en caso de resultar seleccionado, estar preparado para viajar en algunos días a India. Dicha situación podría generar complicaciones en los trabajos, sobre todo si se trata de un lugar donde se exigen formalidades burocráticas, aunque es posible gestionar la autorización con anterioridad y que quede supeditada a la efectiva adjudicación de la beca.

El tercer requisito-si cabe el término-, es la disposición/apertura de mente a una experiencia diferente. India no se circunscribe a la espiritualidad y a la pobreza, más allá de que tales elementos estén presentes en su realidad. El clima, la alimentación, la infraestructura, las costumbres y la vida en general distan de aquello conocido, pero si lejos de juzgar tales aspectos, se asume que se va (también) a conocerlos, estudiarlos y vivirlos, la trayectoria de recorrido de la beca se plantea de manera diferente. A ello debe sumarse que, por ser estudiantes internacionales, también se tendrá la oportunidad de conocer a colegas de otras latitudes, que portan consigo sus propias costumbres y culturas. Por lo tanto, se impone viajar livianos y libres de prejuicios y críticas y al contrario, disponerse a un aprendizaje mayor del inicialmente considerado.

El curso "Crédito rural para la reducción de la pobreza" se desarrolló entre los días 1 y 28 de marzo de 2018, en el campus del prestigioso National Institute of Rural Development and Panchayati Raj (NIRDPR), ubicado en la ciudad de Hyderabad, estado de Telangana. El Instituto consta de numerosos centros de investigación, cuyos Directores fueron los profesores y coordinadores del curso considerado. Su campus cuenta con diversas facilidades como centro de salud, biblioteca, gimnasio con pileta y dos hoteles para albergar a estudiantes nacionales e internacionales. En estos últimos se servían el desayuno, el almuerzo y la cena y los alumnos de los cursos internacionales de ITEC se encontraban alojados en ellos. La interacción con los becarios de otros países, generó que la experiencia fuera rica desde el punto de vista académico, pero también personal.

En la clase de la autora, los participantes eran veinte, de quince países diferentes de Asia Central, Asia del Sur, África y Sudamérica. Algunos de ellos trabajaban como empleados públicos, otros en Organizaciones No Gubernamentales (ONG) y también había académicos de distintas universidades. Los debates entre todos, con tal diversidad de culturas y 
pensamientos, fueron particularmente enriquecedores. Inclusive se tuvo la oportunidad de celebrar "Holi", festividad india muy importante, que celebra la victoria del Bien sobre el Mal, conocida por los polvos de colores, que se arrojan entre las personas que celebran, al grito de "Happy Holi!".

Durante los primeros veinte días del curso, las clases se desarrollaron en el aula y se vieron los siguientes contenidos: estructura del sistema bancario de crédito rural en India; inclusión financiera para el desarrollo rural; servicios bancarios en India; el rol de las pequeñas y medianas empresas en la erradicación de la pobreza; geoinformática; Objetivos de Desarrollo Sostenible de Naciones Unidas; grupos de auto ayuda o Self - Help Groups (SHG); agricultura integrada y sustento sostenible; agricultores pequeños y marginales; desastres nacionales y grupos vulnerables; resiliencia climática y agroforestal; tecnología y desarrollo rural; emprendedurismo social para el desarrollo rural; organizaciones de productores; alfabetización digital; cadenas de valor para el desarrollo rural; oportunidades de auto empleo; auditoría social y accountability; temas de género; crédito rural; seguros de cosechas; procesamiento de alimentos y planificación participativa para la reducción de la pobreza. La mayoría de los profesores poseen el grado de Doctor, en sus respectivas (y diversas) disciplinas y poseean experiencia laboral en las temáticas impartidas. Como cuestión a resaltar, las sesiones fueron abordadas desde un punto de vista neutral y objetivo, explicando inclusive asuntos sensibles, como las implicancias del sistema de castas o la posición de la mujer en India.

Luego de las clases teóricas, los participantes del curso partieron hacia la ciudad de Vishakhapatnam, en el estado de Andhra Pradesh, a realizar una visita de campo, por el término de cinco días. En ella se tuvo la oportunidad de visitar a las comunidades tribales, interactuar con mujeres de diversos SHGs, gerentes y personal bancario, individuos de ONGs y agencias del gobierno estatal. El objetivo principal de esta visita consistió en verificar los contenidos aprendidos en las clases de aula. En esta experiencia se ha podido observar y constatar los esfuerzos desplegados por India para erradicar la pobreza y además, empoderar a las mujeres de zonas rurales, por medio de las microfinanzas.

Asimismo, durante el transcurso del programa, los participantes fueron evaluados en base a una presentación acerca del país de origen de cada alumno, de acuerdo con indicadores relacionados a los conceptos vistos en el curso. Luego, hacia su finalización, se debió presentar un proyecto final, según consignas de índole teórica y las conclusiones obtenidas durante el trabajo de campo. Como derivación de lo dicho al momento, resta mencionar que en todo momento los participantes fueron cuidados como estudiantes internacionales e invitados del gobierno de la India. De hecho, algunos de los compañeros 
de la autora de este artículo, sufrieron problemas de salud y el personal del NIRDPR hizo todo lo necesario para resolver tales problemáticas.

La vivencia de estudiar en India deja muchas enseñanzas. Una cuestión con la que puede uno sorprenderse es el contraste que el país presenta en términos económicos. Su economía crece, según las últimas mediciones, a un $7.2 \%$ anual y esto se ve reflejado, entre otros aspectos, en el desembarco de las empresas de software más prestigiosas del mundo en Hyderabad, convirtiéndola en una "Hi-tex city". Sin embargo, el estado de las calles en las zonas más alejadas, su falta de infraestructura y de higiene no se condicen con ese progreso. Los extranjeros son vistos como novedad y los locales suelen pedirles sacarse fotos con ellos, aunque probablemente haya muchas otras costumbres que no se compartan entre ambos. También se mantienen tradiciones y un tipo de trato diferentes a los que manejan, quienes provienen de otros países de Asia o mismo de África.

Finalmente, cabe señalar que la riqueza de transitar por esta experiencia, amén de adquirir conocimientos específicos, implica asumir y entender aquella unidad en la diversidad, tan pregonada por la India y al mismo tiempo rescatar la extensión, profundidad e importancia del alcance del denominado soft power -en este caso particular, asociado al conocimeintoen la relación entre países, en este caso, Argentina e India.

\section{Referencias}

Banco Interamericano de Desarrollo (2017, diciembre). LATINDIA: El futuro de la cooperación de India y América Latina. Revista Integración \& Comercio, 21 (43). Disponible en https://publications.iadb.org/handle/11319/8726?localeattribute=es\&\#sthash.LMqmya8r.dpuf (accedido por última vez en fecha 09 de abril de 2018).

Hanson, E. C. (2012, Diciembre). India, China and the new public diplomacy. In Presentation at the Indian Association of International Studies/Institute for Research on India and International Studies Convention, The Dawning of the 'Asian Century': Emerging Challenges before Theory and Practices of IR in India, New Delhi.

Nye Jr, J. S. (2008). Public diplomacy and soft power. The annals of the American academy of political and social science, 616(1), 94-109.

Trading Economics. Disponible en https://tradingeconomics.com/

Programa Indian Technical and Economic Cooperation (ITEC). Disponible en: https://www.itecgoi.in 